\title{
Mars Exploration Rover Heat Shield Recontact Analysis
}

\author{
Behzad Raiszadeh \\ NASA Langley Research Center, Hampton, Va., 23681 \\ Prasun Desai \\ NASA Headquarters, Washington D.C., 20546 \\ Robert Michelltree \\ NASA Jet Propulsion Laboratory, Pasadena CA
}

The twin Mars Exploration Rover missions landed successfully on Mars' surface in January of 2004. Both missions used a parachute system to slow the rover's descent rate from supersonic to subsonic speeds. Shortly after parachute deployment, the heat shield, which protected the rover during the hypersonic entry phase of the mission, was jettisoned using push-off springs. Mission designers were concerned about the heat shield recontacting the lander after separation, so a separation analysis was conducted to quantify risks. This analysis was used to choose a proper heat shield ballast mass to ensure successful separation with low probability of recontact. This paper presents the details of such an analysis, its assumptions, and the results. During both landings, the radar was able to lock on to the heat shield, measuring its distance, as it descended away from the lander. This data is presented and is used to validate the heat shield separation/recontact analysis.

\section{Nomenclature}

$A_{B} \quad$ Back shell/lander reference Area

$A_{H} \quad$ Heat shield reference Area

$A_{P} \quad$ Parachute reference Area

$\beta_{B} \quad$ Back shell/lander/parachute ballistic coefficient

$\beta_{H} \quad$ Heat shield ballistic coefficient

$C_{D} \quad$ General term for drag coefficient

$C_{D, B} \quad$ Back shell/lander drag coefficient

$C_{D, H} \quad$ Heat shield drag coefficient

$C_{D, P} \quad$ Parachute drag coefficient

$D \quad$ General term for reference diameter

$D_{B} \quad$ Back shell reference diameter

$D_{H} \quad$ Heat shield reference diameter

$D_{P} \quad$ Parachute reference diameter

$J_{2}, J_{3}, J_{4} \quad$ Gravitational zonal harmonics

$\Delta x \quad$ Axial separation 


$\begin{array}{ll}\Delta z & \text { Lateral separation } \\ m_{B} & \text { Back shell/lander/parachute mass } \\ m_{H} & \text { Heat shield mass } \\ \mu & \text { Planet gravitational constant } \\ \Omega & \text { Planet rotation rate } \\ \rho & \text { Atmospheric density } \\ \sigma & \text { Standard deviation } \\ R_{e} & \text { Planet equatorial radius } \\ R_{p} & \text { Planet polar radius } \\ T & \text { Heat shield separation simulation start time } \\ T_{O} & \text { Time of inertial coordinate system initialization, usually a negative number } \\ V X_{i} & \text { X component of inertial velocity vector } \\ V Y_{i} & \text { Y component of inertial velocity vector } \\ V Z_{i} & \text { Z component of inertial velocity vector } \\ X_{i} & \text { X component of inertial position vector } \\ Y_{i} & \text { Y component of inertial position vector } \\ Z_{i} & \text { Z component of inertial position vector }\end{array}$

\section{Introduction}

All the lander missions to Mars have employed similar Entry Descent, and Landing (EDL) methods in order to safely touch down on Mars' surface. They have all utilized an entry capsule with a forebody heat shield to protected lander during the high aerodynamic heating portion of the atmospheric entry. Once the capsule reaches supersonic speeds, a parachute system is deployed to slow the lander for landing. Once the lander has slowed sufficiently enough to subsonic speeds, the heat shield is jettisoned. In order to minimize the risk of recontact and subsequently damaging the lander, the heat shield must descend faster than the lander/parachute system and not recontact. The twin Mars Exploration Rover (MER) missions both successfully landed on Mars surface in January of 2004, and utilized these EDL principles described as all other previous Mars lander missions (Fig. 1). MER used a separation spring system to push the heat shield away from the lander/parachute system. A successful heat shield separation is a twostep problem. First, the timing and the kinematics of the separation springs have to be such that the heat shield comes off cleanly without recontacting (short term separation). As the heat shield separates, an aerodynamically induced suction force pushes the heat shield back into the lander. The spring system has to impart sufficient impulse to overcome this suction. Second, there has to be a sufficient ballistic coefficient difference between the heat shield and the lander/parachute system such that the heat shield descends faster (long term separation). The focus of this paper is on the long-term separation. 


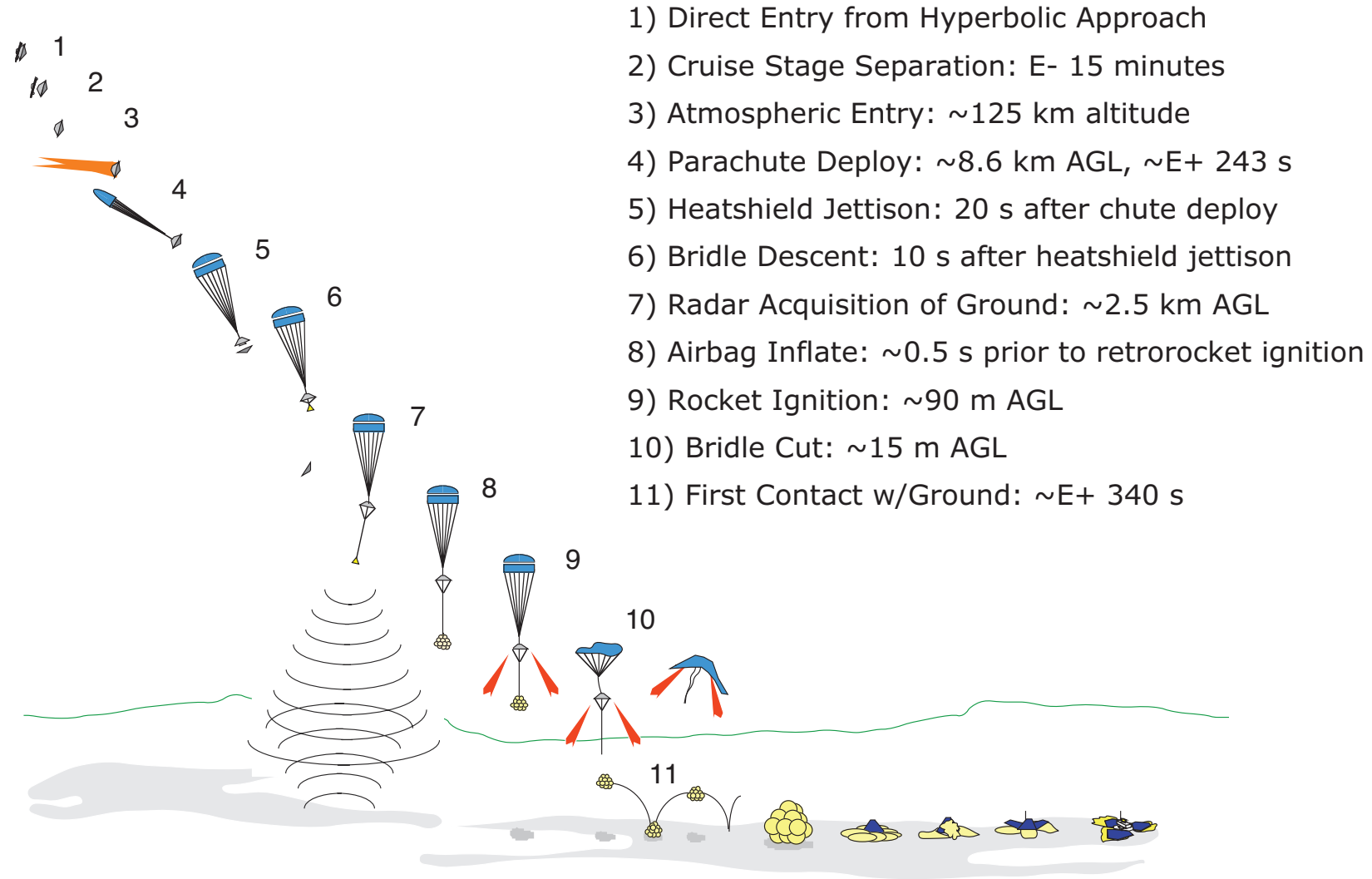

Figure 1. MER Sequence of Events.

\section{Method}

Note that after heat shield separation, what remains is the back shell with the lander attached to it. From this point on, this combined body is referred to as the back shell. In an ideal scenario, the ballistic coefficient of the heat shield would have to be just slightly higher than the back shell/parachute system in order for separation to continue increasing with time. However, there is uncertainty associated with many parameters that play a role in this separation problem. When this analysis was initiated, the rover designs were already somewhat mature, and most parameters affecting this separation problem were already finalized. For example, the diameters of the capsule and the dimensions of the heat shield were set. The overall mass of the mission, the back shell, and the lander mass were also fairly mature. The parachute configuration and its dimensions were known, however there was considerable uncertainty in how much drag the parachute produced on Mars. Mars' atmospheric conditions, namely atmospheric density and winds, carried large uncertainties. The only free parameter that could be varied for the desired heat shield separation performance was the amount of ballast that could be added to the heat shield. Obviously, adding more ballast improves the heat shield separation conditions, but it also increases the overall mass of the entry system. The analysis that is discussed in this paper helped determine the optimum amount of ballast mass to be added to the heat shield such that it would safely separate without recontact and without severely impacting the mass budget of the overall 
EDL system. In order to determine the optimum amount of ballast mass, a series of Monte Carlo simulations were performed to help quantify the probability of heat shield recontact.

\section{Aerodynamic Modeling}

Aerodynamic forces play a major role in the heat shield separation problem. Aerodynamic properties of each body are discussed separately. Note that each body is assumed to be a point mass with three degrees of freedom. Therefore, only the drag force is modeled.

\section{A. Back Shell Aerodynamics}

When in close proximity to each other, an aerodynamic interaction is present between the heat shield and the back shell. This aerodynamic interference needs to be taken into account for simulation accuracy. The twin Viking missions in the 1970's were faced with the same problem. To better understand the close proximity aerodynamics interaction, the Viking project planners set out to quantify the interference aerodynamics between the heat shield and back shell by conducting wind tunnel testings. ${ }^{1}$ The back shell aerodynamic coefficients were extracted from wind tunnel test data as a function of axial $(\Delta \mathrm{x})$ and lateral $(\Delta \mathrm{z})$ separation between the back shell and the heat shield (see Fig. 2). The aerodynamic drag coefficient curves for the back shell and the heat shield from these tests are plotted in Figures 3 and 4 as a function of separation distance (normalized by heat shield diameters).

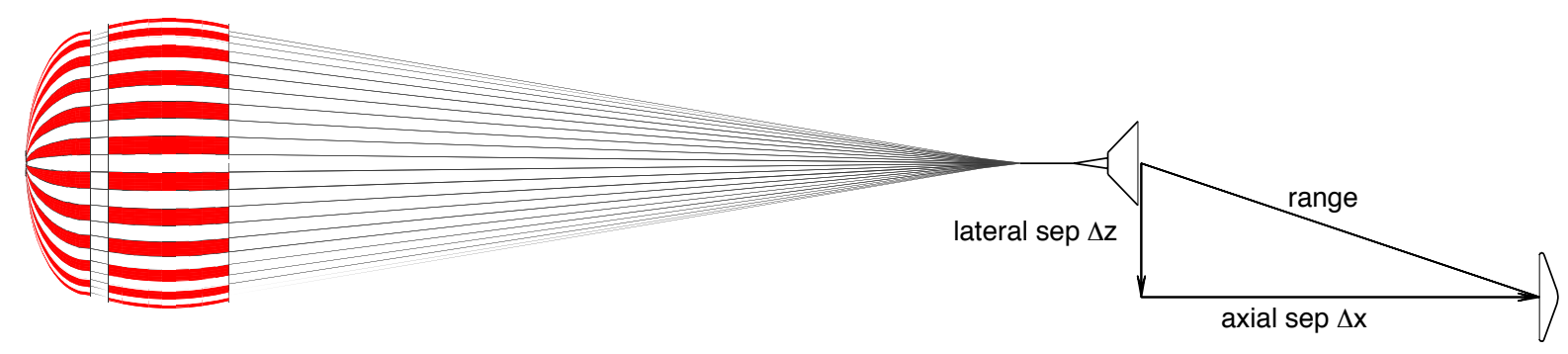

Figure 2. Separation distances.

The interference aerodynamics occurs when two bodies are in close proximately to each other which influence their respective aerodynamics. This interaction effect decreases as their separation distance increases. The tests indicated that when the separation distance is ten heat shield diameters away from the back shell, there is little aerodynamic interference and the back shell aerodynamics approach free stream values. This assumption is valid for lower mach numbers (as is the case during landing), as the drag coefficient curves in Fig. 3 asymptotically approach the steady state free stream value around $\Delta \mathrm{x} / \mathrm{D}$ of ten. This assumption breaks down at Mach 0.75, and more so at Mach 0.95. However, majority of the trajectory is at lower mach numbers, so this assumption has minimal impact on the overall analyses.

Note in Fig. 3 that the drag coefficient is nearly zero up to one diameter of axial separation. The reason for this behavior is because the heat shield shadows the back shell and blocks 
the flow of incoming air. The drag coefficient then becomes negative, meaning the back shell is being "sucked" forward, because of formation of low pressure air flow in the volume between the back shell and the heat shield. Conversely to the "suction" phenomenon on the back shell, the heat shield experiences increased drag in this region (see next subsection). The separation springs need to produce a sufficient impulse to overcome this "suction" force; otherwise the heat shield would simply slam back into the back shell.

As implemented in the simulation, the aerodynamic drag is also a function of lateral separation $\Delta \mathrm{z}$. The drag coefficients remain constant between zero and half diameter lateral separation $(\Delta \mathrm{z} / \mathrm{D}=0.5)$, and then linearly transition to free stream conditions at $\Delta \mathrm{z} / \mathrm{D}=1$ (one diameter of lateral separation). For $\Delta \mathrm{z} / \mathrm{D}>1$, free stream coefficients are used in the simulation. Free stream conditions are the drag coefficient values from Figure 3 at $\Delta x / D=10$. Table 1 summarizes the free stream drag coefficients for the back shell.

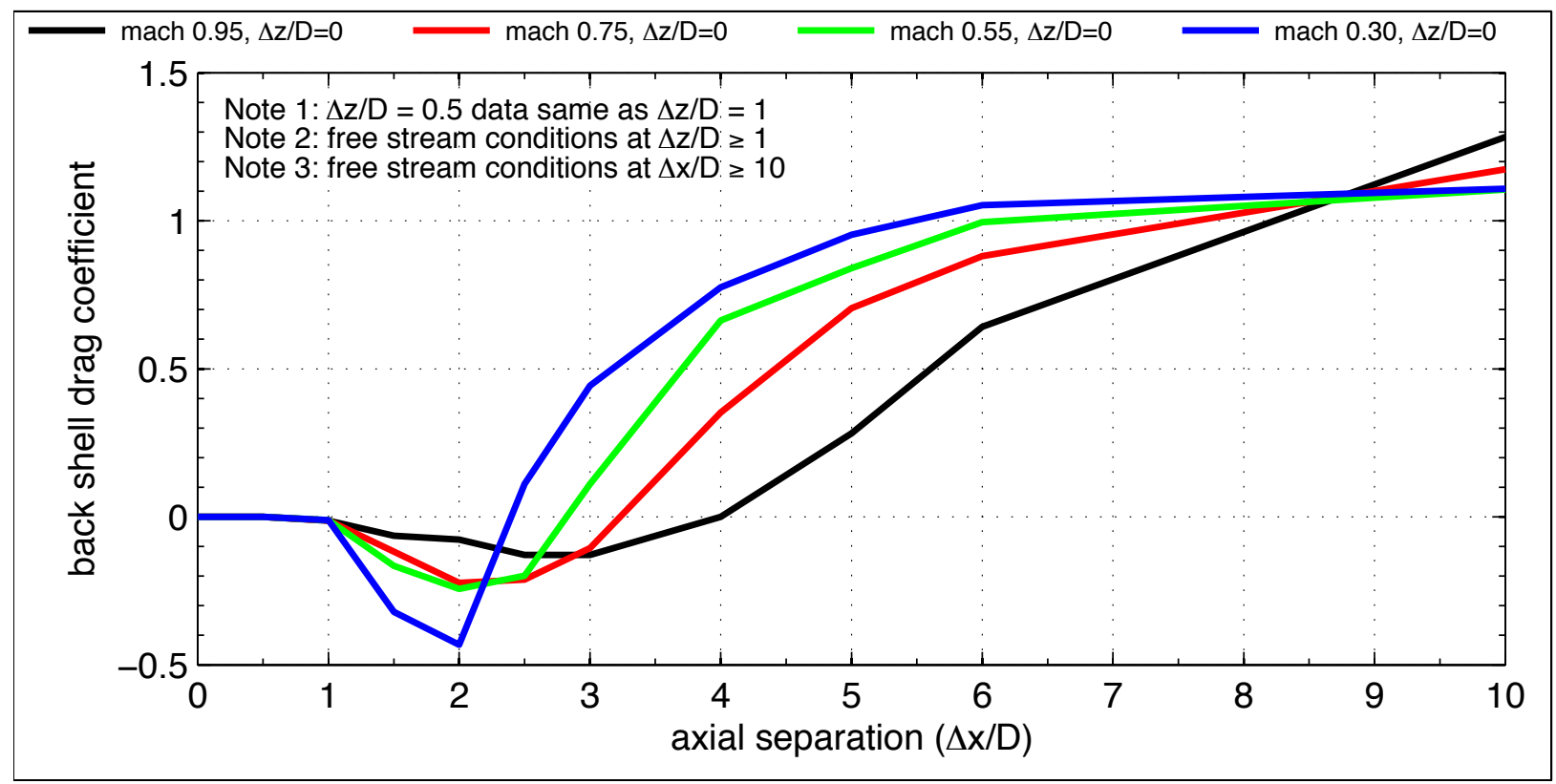

Figure 3. Back shell interference drag aerodynamic coefficient for $\Delta \mathrm{z}=0$.

Table 1. Back shell free stream drag coefficients

\begin{tabular}{cc}
\hline Mach number & Back shell drag coefficient \\
\hline 0.95 & 1.2834 \\
0.75 & 1.1742 \\
0.55 & 1.1058 \\
0.30 & 1.1070 \\
\hline
\end{tabular}




\section{B. Heat Shield Aerodynamics}

Similar to the back shell, the heat shield aerodynamic drag is also affected when in proximity to the back shell. This interference needs to be taken into account to obtain simulation accuracy. The drag coefficient curves for the heat shield are presented in Fig. 4 for four different Mach numbers as a function of axial separation $(\Delta x / D)$ up to ten diameters away. The drag coefficient is a function of both axial and lateral separation. Figure 4 shows the drag coefficient for $\Delta \mathrm{z} / \mathrm{D}=0$ (solid lines) and $\Delta \mathrm{z} / \mathrm{D}$ (dotted lines) $=1$. Drag coefficients for $\Delta \mathrm{z} / \mathrm{D}=3$ are not shown, but were assumed to be the same from $\Delta \mathrm{z} / \mathrm{D}=1$. Free stream conditions were assumed for $\Delta \mathrm{z} / \mathrm{D}$ $>4$. For lateral distances $3 \leq \Delta z / D \leq 4$, the drag coefficient was linearly interpolated. Table 2 summarizes the free stream drag coefficients for the heat shield.

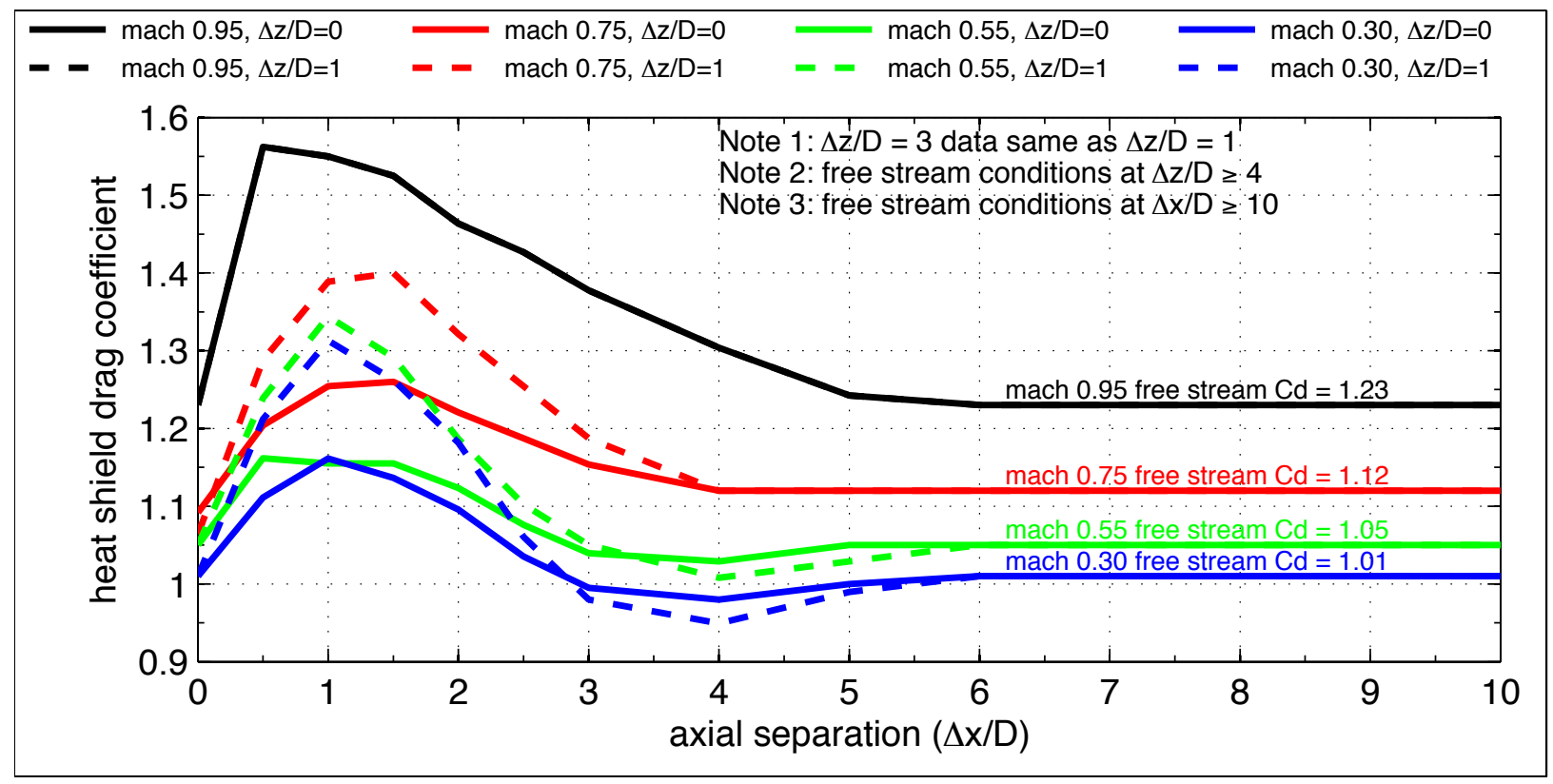

Figure 4. Heat shield interference aerodynamics.

Table 2. Heat shield free stream drag coefficients

\begin{tabular}{cc}
\hline Mach number & Heat shield drag coefficient \\
\hline 0.95 & 1.23 \\
0.75 & 1.12 \\
0.55 & 1.05 \\
0.30 & 1.01 \\
\hline
\end{tabular}

\section{Parachute Aerodynamics}

The parachute drag was incorporated into the simulation by including an additional drag force to the body representing the back shell. The parachute utilized for the MER mission was a Disk-Gap-Band (DGB), same as all other Mars lander missions to date. A constant drag coefficient having a nominal value of 0.41 was used with a $\pm 3 \sigma$ Gaussian distribution of $\pm 12 \%$. ${ }^{2}$ 


\section{Simulation}

The heat shield separation simulation starts at the moment when heat shield jettison command is issued and the separation springs initiate the event (Fig. 5). The vehicle states were handed down from a separate Monte-Carlo simulation of the entry. The heat shield separation problem was simulated using a 3-degree of freedom (DOF) body representing the back shell and another 3-DOF body representing the heat shield. The parachute drag force was accounted for separately and was added to the back shell drag to represent a single back shell/parachute body. The bodies in flight were assumed to follow a gravity turn profile, meaning they always point along the direction of the velocity vector (i.e., zero degrees angle of attack). It was assumed that none of the bodies produce lift; drag force was the only aerodynamic force acting. All simulations were performed using POST II. ${ }^{3}$ Table 3 summarizes the simulation constants, and Table 4 is a summary of parameters that were dispersed statistically in the Monte-Carlo simulations.

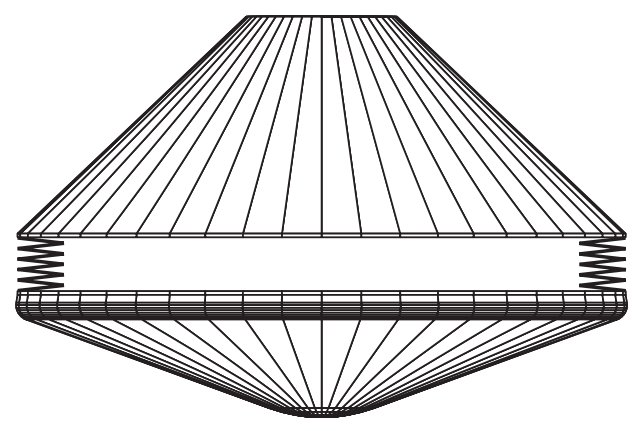

Figure 5. Separation Springs.

Table 3. Simulation constants

\begin{tabular}{llrc}
\hline Variable & \multicolumn{1}{c}{ Description } & \multicolumn{1}{c}{ Value } & Unit \\
\hline$\mu$ & Mars gravitational constant & $4.282838233 \times 10^{13}$ & $\mathrm{~m}^{3} / \mathrm{s}^{2}$ \\
$R_{e}$ & Mars equatorial radius & $3.394200 \times 10^{6}$ & $\mathrm{~m}$ \\
$\mathrm{R}_{\mathrm{P}}$ & Mars polar radius & $3.376780 \times 10^{6}$ & $\mathrm{~m}$ \\
$\Omega$ & Mars rotation rate & $7.088218 \times 10^{-5}$ & $\mathrm{rad} / \mathrm{sec}$ \\
$\mathrm{J}_{2}$ & Mars gravitational zonal harmonic & 0.001958616 & \\
$\mathrm{~J}_{3}, \mathrm{~J}_{4, \ldots}$ & Mars gravitational zonal harmonic & 0.0 & \\
$\mathrm{D}_{\mathrm{B}}$ & Back shell reference diameter & 2.64653 & $\mathrm{~m}$ \\
$\mathrm{D}_{H}$ & Heat shield reference diameter & 2.64653 & $\mathrm{~m}$ \\
$\mathrm{D}_{\mathrm{P}}$ & Parachute reference diameter & 14.1 & $\mathrm{~m}$ \\
$\mathrm{~A}_{B}$ & Back shell reference area & 5.501 & $\mathrm{~m}^{2}$ \\
$\mathrm{~A}_{H}$ & Heat shield reference area & 5.501 & $\mathrm{~m}^{2}$ \\
$\mathrm{~A}_{P}$ & Parachute reference area & 156.124 & $\mathrm{~m}^{2}$ \\
$\mathrm{~m}_{B}$ & Back shell/lander/parachute mass & 737.4 & $\mathrm{~kg}$ \\
$\mathrm{~m}_{H}$ & Heat shield mass & 89.6 & $\mathrm{~kg}$ \\
\hline
\end{tabular}


Table 4 is a list of variables that were dispersed in the heat shield separation Monte-Carlo simulations to account for uncertainty in their values.

Table 4. Monte-Carlo Variables.

\begin{tabular}{clccc}
\hline Variable & \multicolumn{1}{c}{ Description } & Nominal Value & 3 $\sigma$ range & Distribution \\
\hline$\Delta \mathrm{V}$ & Spring induced separation velocity, $\mathrm{m} / \mathrm{s}$ & 2.25 & $\pm 5 \%$ & Gaussian \\
$C_{D, P}$ & Parachute drag coefficient & 0.436 & $\pm 12 \%$ & Gaussian \\
$C_{D, B}$ & Back shell drag coefficient & See Fig. 3 & $\pm 10 \% \& \pm 20 \%$ & See Fig. 6 \\
$C_{D, H}$ & Heat shield drag coefficient & See Fig. 4 & $\pm 10 \% \& \pm 20 \%$ & See Fig. 6 \\
$\rho$ & Atmospheric density, $\mathrm{kg} / \mathrm{m}^{3}$ & & Kass-Schofield model & \\
\hline
\end{tabular}

Engineering judgment was made for aerodynamic uncertainty to be $\pm 20 \%$ when the back shell and the heat shield were in close proximity, and $\pm 10 \%$ in free stream conditions. Specifically, when the heat shield was within three diameters away axially or laterally, an uncertainty of $\pm 20 \%$ Gaussian was utilized. The uncertainty was reduced to $\pm 10 \%$ Gaussian when axial separation $\Delta x / D \geq 10$ or lateral separation $\Delta z / D \geq 4$. Linear interpolation is used for determining uncertainty for distances in between. Figure 6 shows application of this uncertainty approach graphically. This uncertainty was applied to both the heat shield and the back shell drag coefficients.

\section{back shell \& heat shield $C_{D}$ uncertainty}

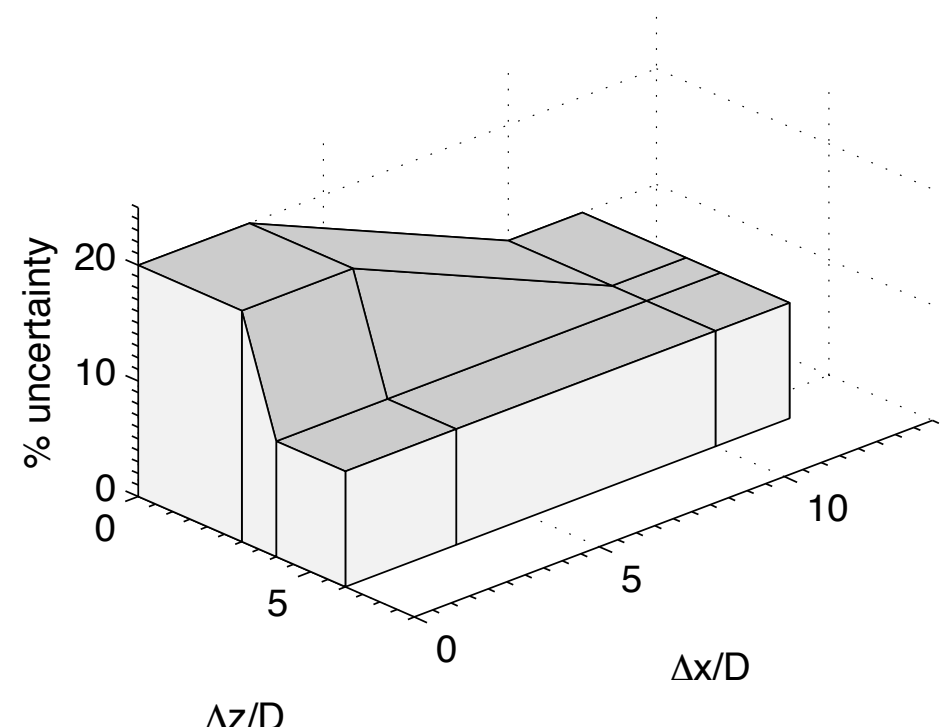

Figure 6. Back shell and heat shield $C_{D}$ uncertainty.

A Mesoscale atmospheric model of Mars' weather was developed for the two MER landing sites (Gusev Crater and Meridiani Planum). This model referred to as the Kass-Schofield model $^{4}$, took into account variations in diurnal, seasonal, positional, and local topography. Figures $7 \mathrm{a}$ and $7 \mathrm{~b}$ show a random sample of 24 density profiles for both locations. The altitude is measured with respect to the local surface. 

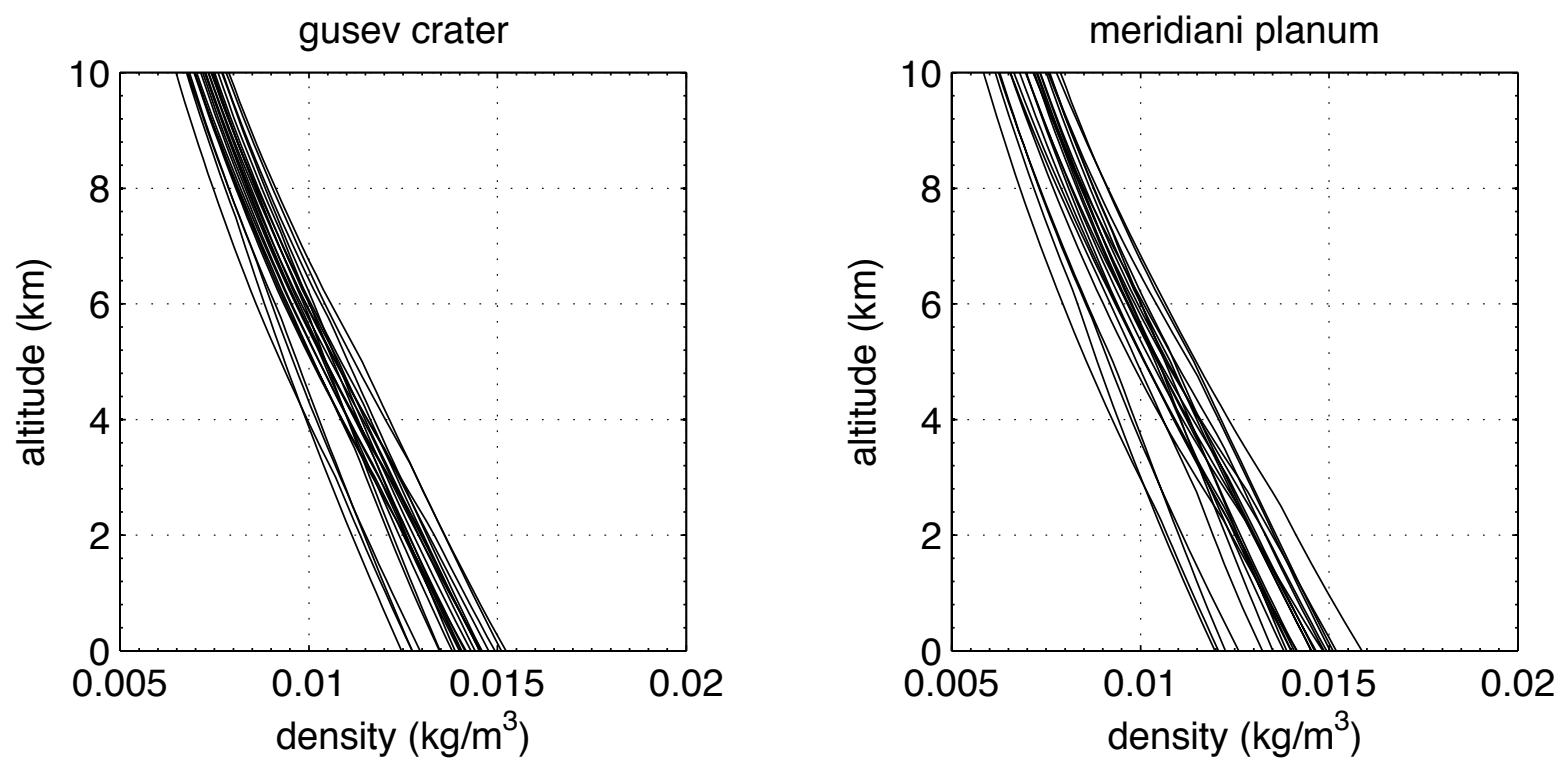

Figure 7a \& 7b. 24 random density profiles at Gusev Crater and Meridiani Planum.

Heat shield separation simulation state vectors were handed down from another entry simulation. ${ }^{5}$ States were provided in a Cartesian inertial coordinate system with the planet's center as origin. Separation time and the time the inertial coordinate system was initialized are also included along with the state vectors in Tables 5 and 6 for MER-A and MER-B, respectively. Note the column designated as "Nominal Value" contains values that were used in the baseline, unperturbed trajectory simulation, and the mean value is the average of all the runs. The nominal value and the mean value are close but not exactly the same.

Table 5. MER-A Heat Shield Separation States.

\begin{tabular}{|c|c|c|c|c|c|}
\hline Variable & Description & $\begin{array}{r}\text { Nominal } \\
\text { Value }\end{array}$ & $\begin{array}{l}\text { Mean } \\
\text { Value }\end{array}$ & $3 \sigma$ range & Distribution \\
\hline$T$ & Time at separation (sec) & 323.5 & 323.8 & \pm 2.3 & Gaussian \\
\hline$X_{i}$ & Inertial position, $X$ component $(\mathrm{m})$ & $-2,245,230.8$ & $-2,244,507.6$ & $\pm 5,338.1$ & Gaussian \\
\hline$Y_{i}$ & Inertial position, $\mathrm{Y}$ component $(\mathrm{m})$ & $-2,404,396.4$ & $-2,404,798.9$ & $\pm 5,014.8$ & Gaussian \\
\hline$Z_{i}$ & Inertial position, $Z$ component (m) & $-856,501.9$ & $-856,939.8$ & $\pm 2,017.5$ & Gaussian \\
\hline $\mathrm{VX}_{\mathrm{i}}$ & Inertial velocity, $X$ component $(\mathrm{m})$ & 272.4 & 271.8 & \pm 5.6 & Gaussian \\
\hline$V Y_{i}$ & Inertial velocity, $\mathrm{Y}$ component $(\mathrm{m})$ & -152.0 & -150.9 & \pm 2.3 & Gaussian \\
\hline$V Y_{i}$ & Inertial velocity, $Z$ component (m) & 50.5 & 49.8 & \pm 2.2 & Gaussian \\
\hline
\end{tabular}

Note: Time of inertial coordinate system initialization $T_{0}=-12,406.3 \mathrm{sec}$. for all runs 
Table 6. MER-B Heat Shield Separation States.

\begin{tabular}{|c|c|c|c|c|c|}
\hline Variable & Description & $\begin{array}{r}\text { Nominal } \\
\text { Value }\end{array}$ & $\begin{array}{l}\text { Mean } \\
\text { Value }\end{array}$ & $3 \sigma$ range & Distribution \\
\hline $\mathrm{T}$ & Time at separation (sec) & 322.8 & 323.3 & \pm 5.3 & Gaussian \\
\hline$X_{i}$ & Inertial position, $\mathrm{X}$ component (m) & $-2,547,425.3$ & $-2,545,840.7$ & $\pm 13,659.8$ & Gaussian \\
\hline$Y_{i}$ & Inertial position, Y component (m) & $-2,248,551.6$ & $-2,250,458.5$ & $\pm 15,172.7$ & Gaussian \\
\hline$Z_{i}$ & Inertial position, $Z$ component (m) & $-118,767.2$ & $-118,049$ & $\pm 1,807.7$ & Gaussian \\
\hline$V X_{i}$ & Inertial velocity, X component (m) & 268.4 & 271.2 & \pm 6.4 & Gaussian \\
\hline$V Y_{i}$ & Inertial velocity, Y component (m) & -180.1 & -180.9 & \pm 3.4 & Gaussian \\
\hline$V Y_{i}$ & Inertial velocity, Z component (m) & 14.1 & 12.3 & \pm 2.2 & Gaussian \\
\hline
\end{tabular}

Note: Time of inertial coordinate system initialization $T_{0}=-55,691.2 \mathrm{sec}$. for all runs

\section{Determining Heat Shield Ballast Mass}

It was determined early on in the MER project that without any additional mass on the heat shield, recontact would be an issue. The analysis techniques outlined in this section were used to determine how much ballast mass should be added to the heat shield to minimize recontact risk. This risk was statistically quantified using Monte-Carlo simulations, and allowed the EDL team to determine the ballast mass that mitigated the risk while at the same time was not excessively heavy as the MER project was very mass constrained. Numerous Monte-Carlo simulations were run and within each set the effect of each parameter was examined on the overall performance. The results of all Monte-Carlo runs will not be discussed; instead representative samples plots are shown to provide an understanding of the analysis techniques utilized to determine the most appropriate heat shield ballast mass. A heat shield separation success criterion was established: if the heat shield was 21 meters away in 13 seconds, it was considered a successful separation. The push off springs caused a positive separation initially, but because of interference aerodynamics (i.e., the suction force), the heat shield could potentially come back and strike the back shell in some cases. Such scenario would be considered an unsuccessful separation even though there was a positive separation at first. It was determined through many MonteCarlo analyses that if the heat shield made it as far as 21 meters in 13 seconds in the simulation, it was guaranteed to continue descending away from the back shell. In each Monte-Carlo set, the percentage of cases that violated this criterion was recorded. One concern initially was if the parachute does not produce the desired drag. Figures $8 \mathrm{a}$ and $8 \mathrm{~b}$ show the contour plots of percentage of cases that recontacted if the parachute did to produce the expected $\mathrm{C}_{\mathrm{D}} \mathrm{A}$ and remained at a constant reduced value within each Monte-Carlo set. All other parameters were perturbed in these Monte-Carlo simulations. Note that nominal $C_{D} A$ of $67.5 \mathrm{~m}^{2}$ is to the right for both plots where the likelihood of recontact is practically zero. 

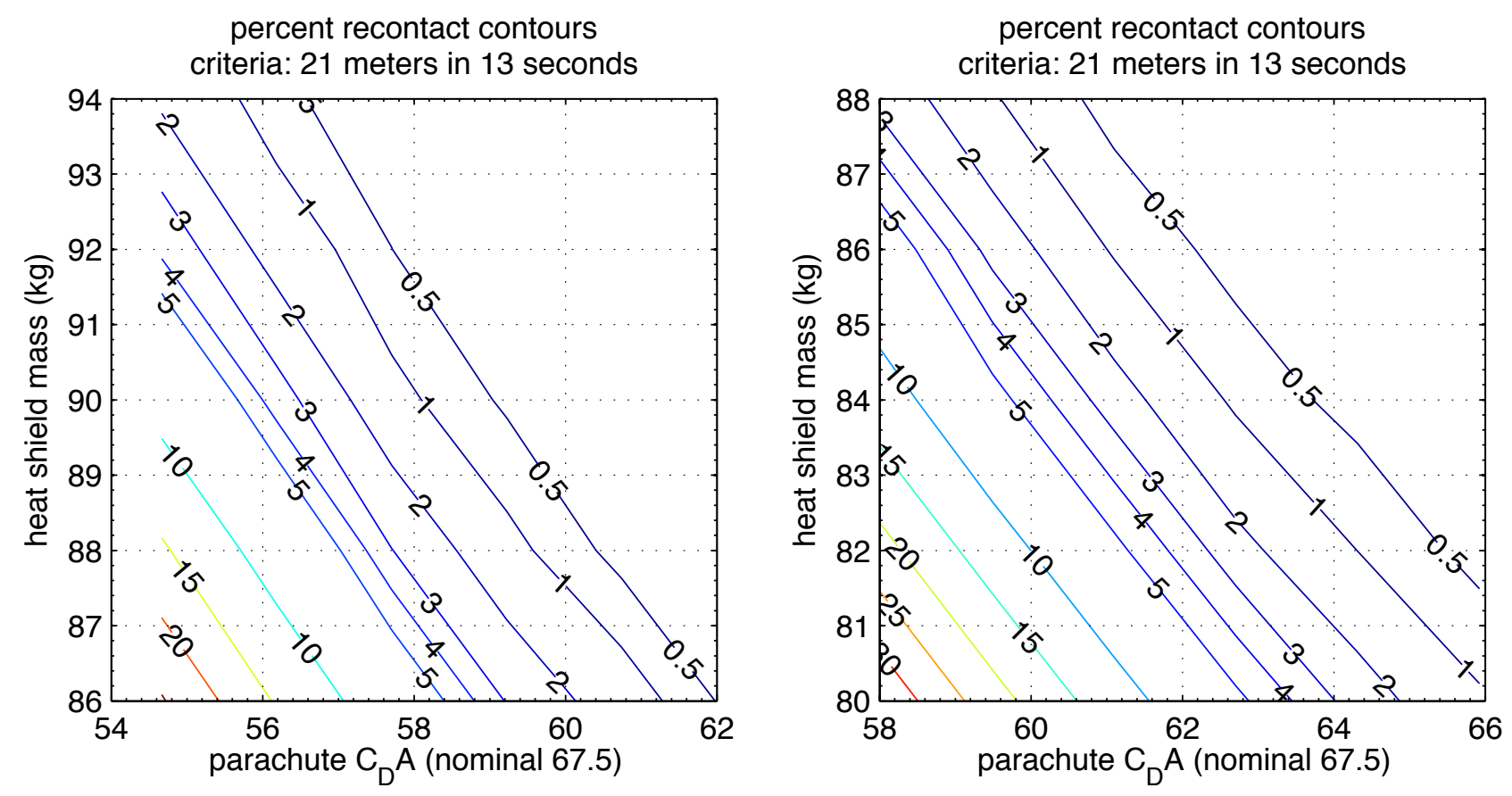

Figure 8a \& 8b. Percentage recontact contours $\left(C_{D} A\right.$ units $\left.m^{2}\right)$.

Figures $8 \mathrm{a}$ and $8 \mathrm{~b}$ explore different regions of the design space. Figure 9 shows the data from Figures $8 \mathrm{a}$ and $8 \mathrm{~b}$ combined and displayed differently. The number next to each curve indicates the percentage reduction in parachute $C_{D} A$ from nominal $C_{D} A$ of $67.5 \mathrm{~m}^{2}$.

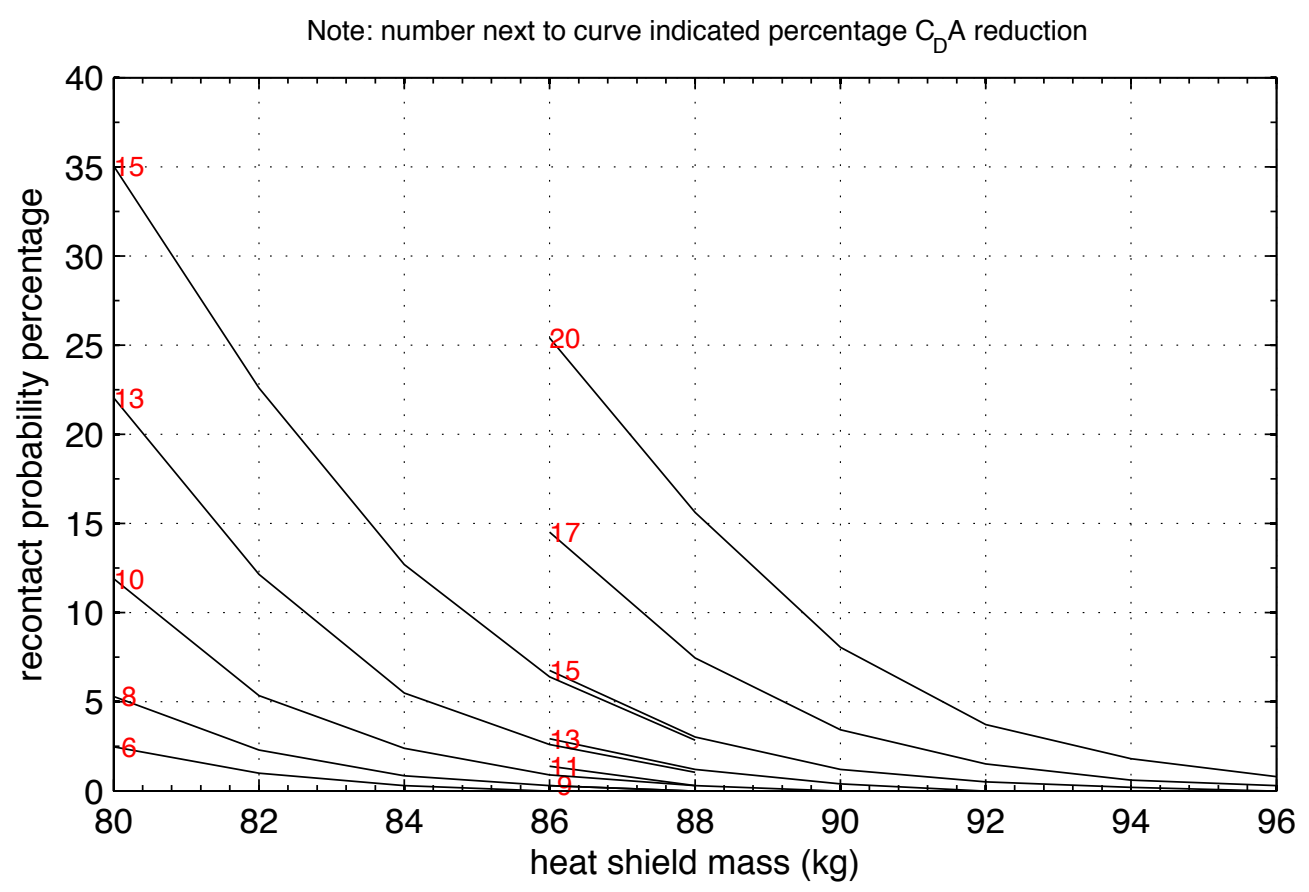

Figure 9. Recontact probability vs. heat shield mass. 
The conservatism obtained from adding excessive amount of ballast mass would come at the expense of the overall project mass budget. So the mission designers had to strike a balance between what kind of recontact risk was acceptable and the amount of ballast to be added to the heat shield. Simulation results such as the data shown in Figs. 8a, 8b, and 9 were used in the decision process. Normally, in a Monte-Carlo simulation, a variable such as the parachute drag would be perturbed in each run based on either uniform or Gaussian distribution. In the data presented in Figs. 8a, 8b, and 9, additional conservatism was exercised by reducing the parachute drag by a percentage for all the runs in each particular Monte-Carlo set. Through this analysis, ballast masses were added to bring heat shield masses up to $89.6 \mathrm{~kg}$ for MER-A ("Spirit") and 89.5 for MER-B ("Opportunity"). Given the final heatshield masses, in a worst-case scenario, if the parachute produced 10-12 percent less drag in all cases, the probability of recontact would still be very small, on the order of 1 or 2 percent (lower region of Fig. 11 in the middle).

\section{Day of Entry Simulation Results}

Once both MER-A and MER-B were launched, the EDL team no longer had control over the heat shield mass. This section summarizes the results of the last simulations performed before both rovers entered the Martian atmosphere. The purpose of these simulations was to make sure there was minimal risk of heat shield recontact given the expected day-of-entry conditions. During the cruise phase, the EDL team had the option of tweaking the trajectory to change entry conditions and timing of the entire EDL sequence if needed. The heat shield recontact simulations were run a few days before entry to make sure there was still plenty of separation margin. Day-of-entry heat shield recontact simulations were run using the final heat shield mass, and the most up to date available navigated entry states. Tables $7 \mathrm{a}$ and $7 \mathrm{~b}$ report the position of the heat shield with respect to the body coordinate system of the back shell at a few discrete time intervals. $X$ axis of the back shell point directly forward, so positive $X$ means the heat shield is in front of the back shell (see Fig. 2). Such output was generated and reviewed after each MonteCarlo set to make sure there was positive separation in all cases. In particular, separation statistics after 13 seconds were examined to make certain there was 21 meters of separation according

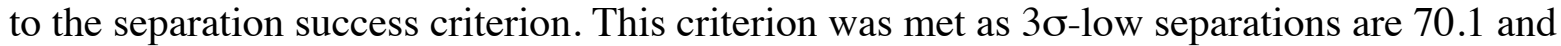
67.8 meters for MER-A and MER-B, respectively, as well as the minimum separation distances of $59.5 \mathrm{~m}$ and $56.9 \mathrm{~m}$, respectively. 
Table 7a. MER-A day-of-entry Monte-Carlo Results

\begin{tabular}{|c|c|c|c|c|c|}
\hline Description & mean & 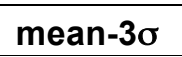 & 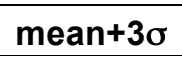 & $\min$. & max. \\
\hline Altitude at separation & $6,975.1$ & $5,019.2$ & $8,931.0$ & $4,861.3$ & $8,959.8$ \\
\hline Altitude after $5 \mathrm{sec}$. & $6,552.3$ & $4,597.6$ & $8,506.9$ & $4,446.6$ & $8,513.9$ \\
\hline Axial Separation after $5 \mathrm{sec}$. & 25.8 & 13.5 & 38.2 & 12.0 & 38.7 \\
\hline Lateral Separation after $5 \mathrm{sec}$. & 2.1 & 1.2 & 3.0 & 1.2 & 3.2 \\
\hline Net range after $5 \mathrm{sec}$. & 25.9 & 13.5 & 38.3 & 12.1 & 38.8 \\
\hline Altitude after $10 \mathrm{sec}$. & $6,136.2$ & $4,185.0$ & $8,087.5$ & $4,027.3$ & $8,077.1$ \\
\hline Axial Separation after $10 \mathrm{sec}$. & 80.6 & 43.7 & 117.6 & 36.8 & 117.6 \\
\hline Lateral Separation after $10 \mathrm{sec}$. & 12.0 & 6.2 & 17.8 & 5.5 & 18.7 \\
\hline Net range after 10 sec. & 81.5 & 44.1 & 118.9 & 37.2 & 119.1 \\
\hline Altitude after $13 \mathrm{sec}$. & $5,888.1$ & $3,939.5$ & $7,836.7$ & $3,774.2$ & $7,817.6$ \\
\hline Axial Separation after $13 \mathrm{sec}$. & 122.7 & 69.1 & 176.2 & 58.6 & 175.4 \\
\hline Lateral Separation after $13 \mathrm{sec}$. & 22.9 & 11.9 & 33.8 & 10.4 & 35.7 \\
\hline Net range after $13 \mathrm{sec}$. & 124.8 & 70.1 & 179.4 & 59.5 & 179.0 \\
\hline Altitude after $20 \mathrm{sec}$. & $5,310.0$ & $3,367.9$ & $7,252.0$ & $3,179.8$ & $7,214.9$ \\
\hline Axial Separation after $20 \mathrm{sec}$. & 235.1 & 141.5 & 328.7 & 121.9 & 329.2 \\
\hline Lateral Separation after $20 \mathrm{sec}$. & 61.5 & 32.6 & 90.3 & 29.2 & 95.6 \\
\hline Net range after $20 \mathrm{sec}$. & 243.0 & 145.3 & 340.8 & 125.4 & 340.8 \\
\hline
\end{tabular}

Note: all units of distance are in Meters (m)

Table 7b. MER-B Day-of-Entry Monte-Carlo Results

\begin{tabular}{lrrrrr}
\hline Description & mean & mean $\mathbf{- 3 \sigma}$ & \multicolumn{1}{c}{$\boldsymbol{+ \mathbf { 3 } \sigma}$} & \multicolumn{1}{c}{ min. } & \multicolumn{1}{c}{ max. } \\
\hline Altitude at separation & $5,942.8$ & $3,649.1$ & $8,236.5$ & $3,013.6$ & $8,214.6$ \\
\hline Altitude after 5 sec. & $5,528.4$ & $3,236.1$ & $6,820.7$ & $2,609.1$ & $7,820.6$ \\
Axial Separation after 5 sec. & 25.7 & 12.9 & 38.5 & 11.5 & 40.7 \\
Lateral Separation after 5 sec. & 2.2 & 1.2 & 3.1 & 1.1 & 3.3 \\
Net range after 5 sec. & 25.8 & 13.0 & 38.7 & 11.5 & 40.8 \\
\hline Altitude after 10 sec. & $5,122.0$ & $2,832.5$ & $7,411.4$ & $2,202.0$ & $7,427.0$ \\
Axial Separation after 10 sec. & 80.0 & 42.2 & 117.9 & 35.0 & 122.6 \\
Lateral Separation after 10 sec. & 12.3 & 6.1 & 18.4 & 5.3 & 19.6 \\
Net range after 10 sec. & 81.0 & 42.6 & 119.3 & 35.4 & 124.1 \\
\hline Altitude after 13 sec. & $4,879.9$ & $2,592.1$ & $7,167.6$ & $1,956.5$ & $7,190.5$ \\
Axial Separation after 13 sec. & 121.3 & 66.8 & 175.9 & 56.0 & 180.8 \\
Lateral Separation after 13 sec. & 23.3 & 11.6 & 35.0 & 10.0 & 37.7 \\
Net range after 13 sec. & 123.5 & 67.8 & 179.3 & 56.9 & 184.7 \\
\hline Altitude after 20 sec. & $4,316.1$ & $2,030.9$ & $6,601.3$ & $1,378.8$ & $6,636.8$ \\
Axial Separation after 20 sec. & 230.9 & 136.5 & 325.3 & 117.0 & 334.2 \\
Lateral Separation after 20 sec. & 62.4 & 31.8 & 93.0 & 28.4 & 101.4 \\
Net range after 20 sec. & 239.2 & 140.2 & 338.1 & 120.4 & 348.2 \\
\hline
\end{tabular}

Note: all units of distance are in Meters $(\mathrm{m})$

Figures 10 and 11 show planet relative velocity and flight path angle profiles for 24 random day-of-entry Monte-Carlo trajectory simulations. Figure 10 shows how in all cases the heat shield has a higher velocity than the back shell. Figure 11 is interesting in that the entire system is still moving at a fairly steep angle of -45 to -50 degrees flight path angle at separation. The 
back shell trajectory bends towards vertical more rapidly than the heat shield because of its higher drag.

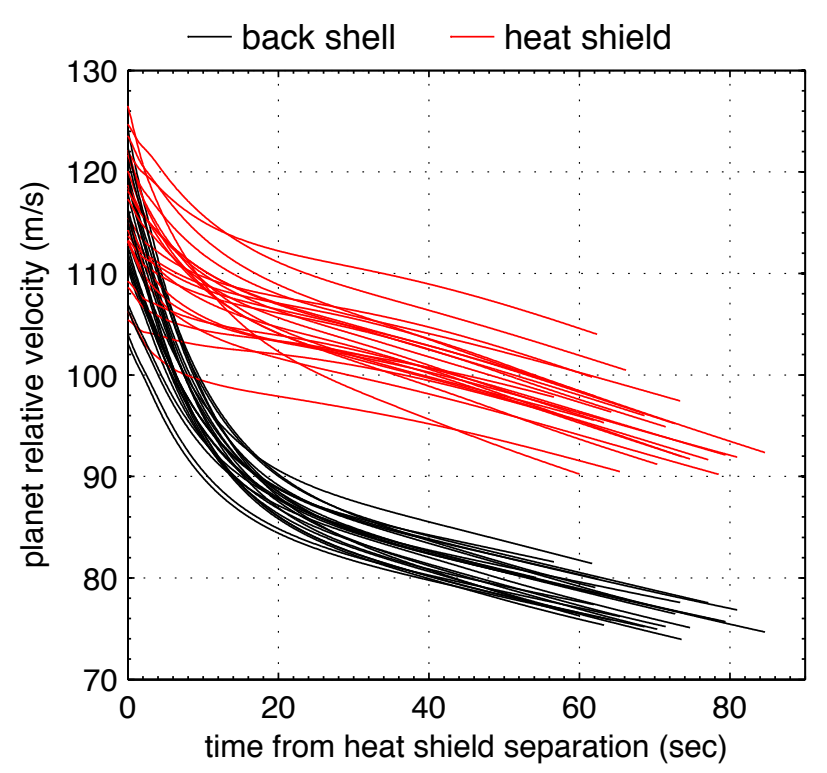

Figure 10. Planet relative velocity.

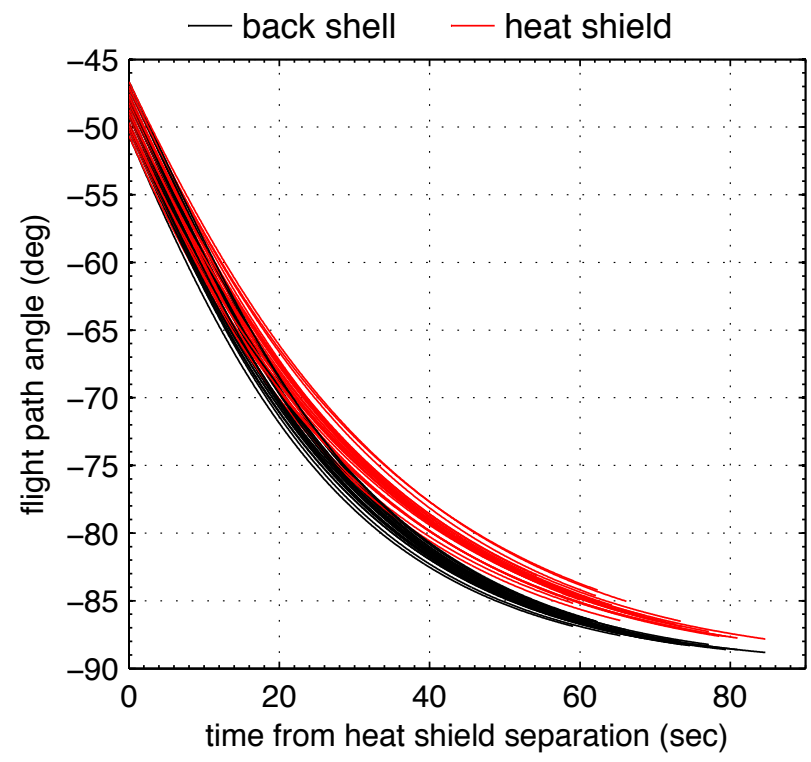

Figure 11. Planet relative flight path angle.

\section{Flight Data Correlation}

During descent of both landers, the radar fortuitously locked on to the heat shield and measured its range for a few seconds. Figs. 12a and 12b show heat shield separation statistical data from the Monte-Carlo simulations along with flight data for both MER-A and MER-B, respectively. In both cases, the separation flight data is well within the statistical bounds and not far from nominal predictions. For both rovers, the heat shield distance to the back shell increased faster than the nominal analytical predictions, indicating that simulation assumptions were conservative. There was no direct measurement of drag forces on the parachute or the heat shield, so it is difficult to make a definite claim about the cause of the discrepancy. In the simulation, it was assumed that the heat shield was always facing the flow directly (zero degrees angle of attack assumption). It is possible that the heat shield deviated from this assumption and descended at some angle of attack thus reducing aerodynamic drag forces, and descending faster than the predicated rate. Another explanation could be that the parachute produced more drag force than the predictions. Figs. 13a and $13 \mathrm{~b}$ show the same data as $12 \mathrm{a}$ and $12 \mathrm{~b}$ with focus on the flight data. 


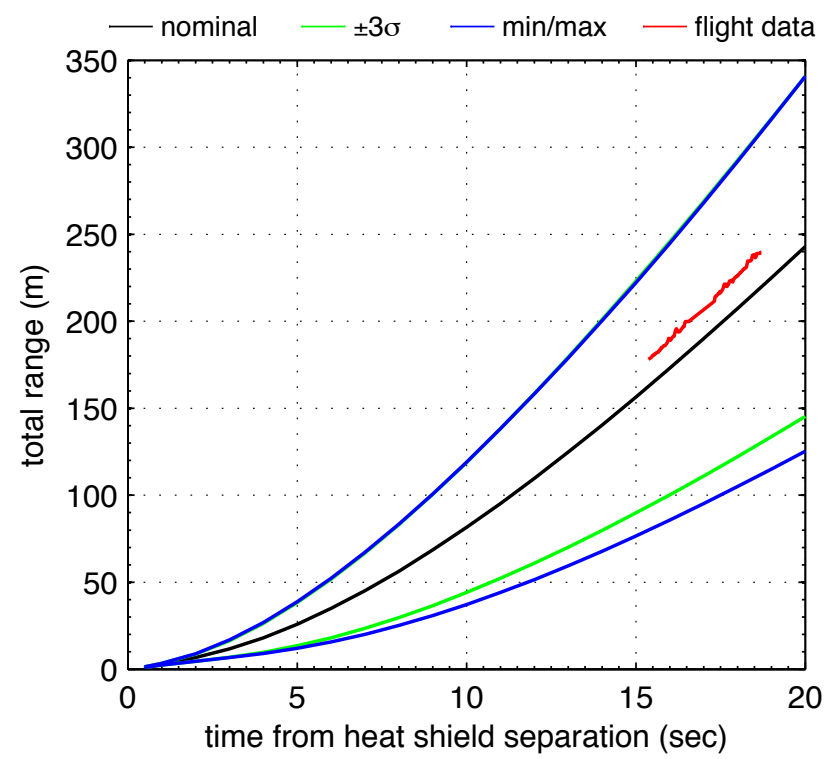

Figure 12a. Total range for MER-A.

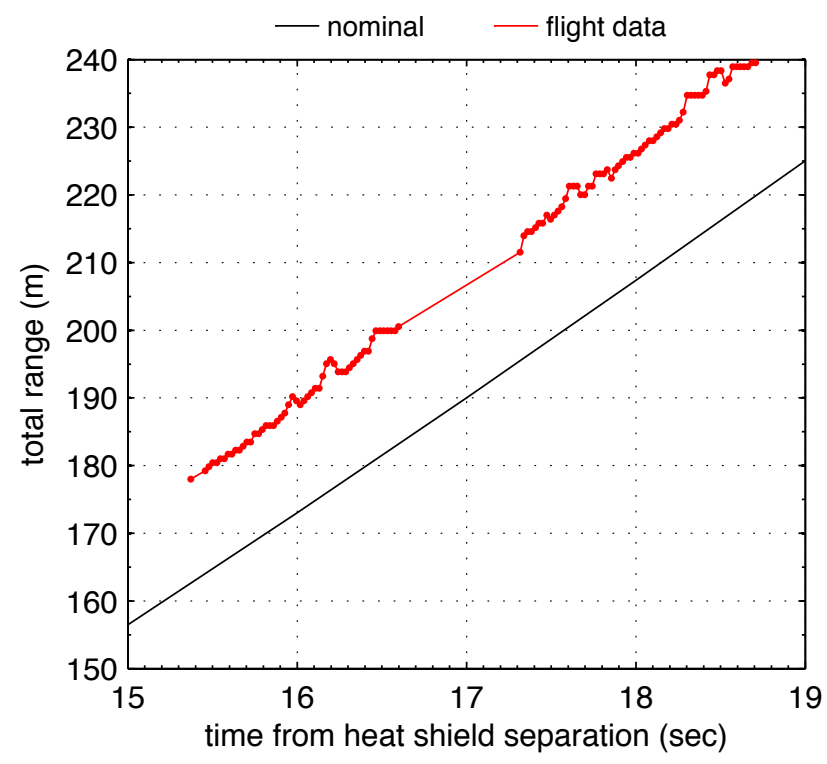

Figure 13a. MER-A radar flight data.

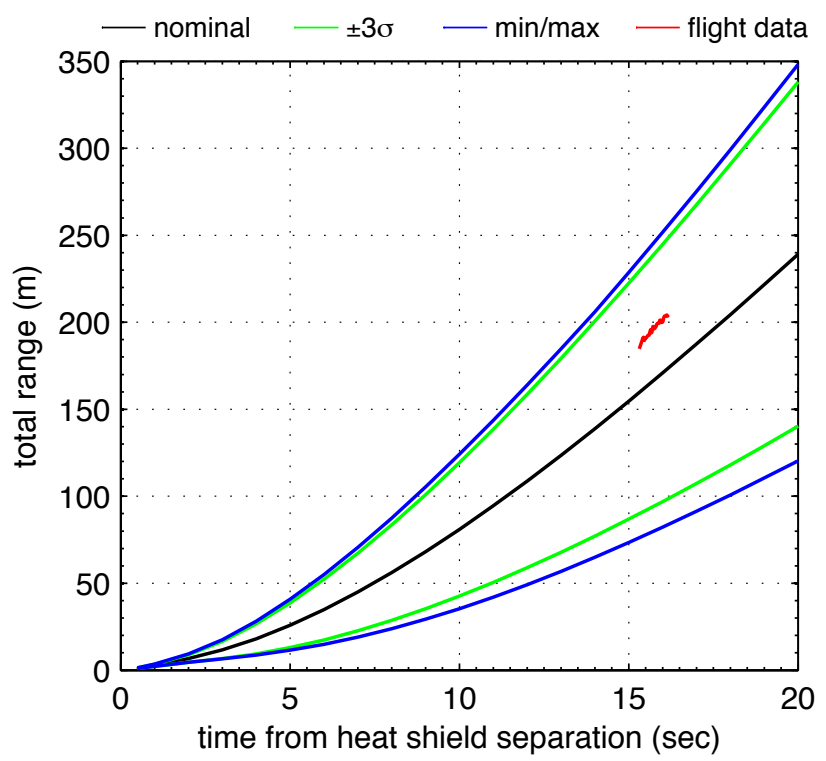

Figure 12b. Total range for MER-B.

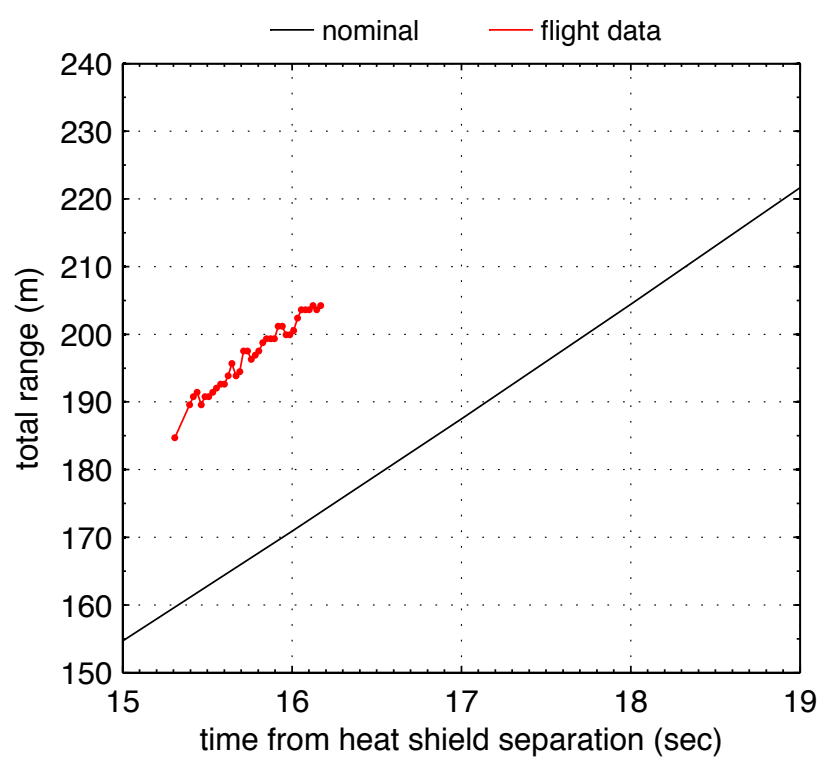

Figure 13b. MER-B radar flight data.

\section{Conclusions}

A separation analysis was performed for the Mars Exploration Rover (MER) missions to prevent heat shield recontact. A Monte-Carlo simulation was constructed to statistically quantify this risk. This paper discusses how the simulation was put together, assumptions, and the analytical techniques in order to enable the EDL team assess the heat shield separation risk numerically, and allow them to make decisions to minimize the recontact risk. The method and techniques outlined in this paper proved successful in ensuring the heat shield did not recontact the lander 
during entry for both of the MER landings. The as-radar-measured separation distance of the heat shield was close to the nominal predictions (within 10\% for MER-A and $18 \%$ for MER-B). For both landings, the heat shield distance to the back shell increased faster than the nominal analytical predictions, indicating that simulation assumptions were conservative. Theoretically, if perfect knowledge was available for every variable that plays a role in the heat shield separation problem, the heat shield ballistic coefficient would only have to be just slightly higher than the back shell/parachute combination for a safe heat shield separation event. For the MER heat shield separation problem, major contributors to simulation uncertainty were initial states, Mars' atmospheric density, and lander aerodynamics including interference aerodynamics. Mission designers for every new planetary mission with similar EDL architecture have to ensure that the heat shield separates cleanly and does not recontact and cause damage to precious cargo. This risk can be reduced by adding ballast mass to the heat shield, if recontact is judged to be a problem. For the MER missions, the ballistic coefficient of the heat shield ended up being approximately 60 percent higher than the back shell and parachute combined. It is recommended that future missions use similar arrangement as a starting point.

\section{Acknowledgments}

The authors would like to thank others that have made contributions to this paper to include Robin Bruno, and Wayne Lee from Jet Propulsion Laboratory. Special thanks should go to Scott Shaffer from the Jet Propulsion Laboratory for providing the heat shield separation radar data during entry. It is a privilege to include Robert (Bob) Mitcheltree as one of the co-authors. He tragically died in a car accident in January of 2006. Bob dedicated a major part of his career to Mars exploration, and was a major contributor in MER's success. Bob left a void in Mars and planetary exploration and personally as a friend.

\section{References}

[1] J. R. Lang, D. A. Sarver, "Experimental aerodynamic Characteristics of the Viking Lander Capsule During Aeroshell Staging”, Martin Marietta Report TR-3720301, September 1972 (under contract NAS1-9000).

[2] P. N. Desai, J. T. Schofield, and M. E. Lisano, "Flight Reconstruction of the Mars Pathfinder Disk-Gap-Band Parachute Drag Coefficients," Journal of Spacecraft and Rockets, Vol. 42, No. 4, July-August 2005.

[3] R. W. Powell, S. A. Striepe, P. N. Desai, P. V. Tartabini, E.M. Queen from NASA Langley Research Center, and by: G. L. Brauer, D. E. Cornick, D. W. Olson, F. M. Petersen, R. Stevenson, M. C. Engel, S. M. Marsh from Lockheed Martin Corporation, "Program to Optimize Simulated Trajectories: Volume II, Utilization Manual”, Version 1.1.1.G, May 2000.

[4] D. M. Kass, J. T. Schofield, T. I. Michaels, S. C. Rafkin, M. I. Richardson, A. D. Toigo, "Analysis of Atmospheric Mesoscale Models of Entry, Descent, and Landing," Journal of Geophysical Research, Vol. 108, No. E12, 25 Nov. 2003, pp. ROV 31-1 to ROV 21-12. 
[5] P. N. Desai, M. Schoenenberger, and F. M. Cheatwood, "Mars Exploration Rover SixDegree-of-Freedom Entry Trajectory Analysis," Journal of Spacecraft and Rockets, Vol. 43, No. 5, September-October 2006. 